\title{
Global precipitation response to changing forcings since 1870
}

\author{
A. Bichet, M. Wild, D. Folini, and C. Schär \\ Institute for Atmospheric and Climate Sciences, ETH Zürich, Switzerland \\ Received: 5 January 2011 - Published in Atmos. Chem. Phys. Discuss.: 22 March 2011 \\ Revised: 15 August 2011 - Accepted: 5 September 2011 - Published: 27 September 2011
}

\begin{abstract}
Predicting and adapting to changes in the hydrological cycle is one of the major challenges for the 21st century. To better estimate how it will respond to future changes in climate forcings, it is crucial to understand how the hydrological cycle has evolved in the past and why. In our study, we use an atmospheric global climate model with prescribed sea surface temperatures (SSTs) to investigate how, in the period 1870-2005, changing climate forcings have affected the global land temperature and precipitation. We show that between 1870 and 2005, prescribed SSTs (encapsulating other forcings and internal variability) determine the decadal and interannual variabilities of the global land temperature and precipitation, mostly via their influence in the tropics $\left(25^{\circ} \mathrm{S}-25^{\circ} \mathrm{N}\right)$. In addition, using simulations with prescribed SSTs and considering the atmospheric response alone, we find that between 1930 and 2005 increasing aerosol emissions have reduced the global land temperature and precipitation by up to $0.4{ }^{\circ} \mathrm{C}$ and $30 \mathrm{~mm} \mathrm{yr}^{-1}$, respectively, and that between about 1950 and 2005 increasing greenhouse gas concentrations have increased them by up to $0.25^{\circ} \mathrm{C}$ and $10 \mathrm{~mm} \mathrm{yr}^{-1}$, respectively. Finally, we suggest that between about 1950 and 1970, increasing aerosol emissions had a larger impact on the hydrological cycle than increasing greenhouse gas concentrations.
\end{abstract}

\section{Introduction}

Global and regional variations in temperature and precipitation are key parameters affecting our economy and ecosystems. To better predict their changes under future climate conditions, it is essential to understand their sensitivity to the relevant climate forcings, and how this sensitivity evolves

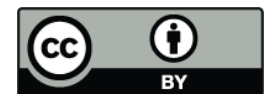

Correspondence to: A. Bichet (adeline.bichet@env.ethz.ch) through time. Based on observations, previous studies (e.g. Allen and Ingram, 2002; Wild et al., 2008; Wild and Liepert, 2010) show the crucial role of the radiation balance in driving the hydrological cycle, and point out the important role of aerosol and greenhouse gas concentrations. On the one hand, increasing aerosol concentrations in the atmosphere is expected to cool the Earth's surface and reduce precipitation (e.g. Ramanathan et al., 2001; Liepert et al., 2004; Wild et al., 2005; Wild and Liepert, 2010). On the other hand, increasing greenhouse gas concentrations in the atmosphere is expected to warm the Earth's surface and increase precipitation (e.g. Trenberth, 1990; Boer, 1993; IPCC AR4, 2007; Trenberth, 2011). Recent studies (e.g. Wild et al., 2007 and 2008; Wild and Liepert, 2010) suggest that between about 1960 and 1980, increasing aerosol concentrations had a larger impact on the global land temperature and precipitation than increasing greenhouse gas concentrations, whereas the opposite is true after about 1980.

The atmospheric forcings addressed affect the coupled climate system in intricate ways. Changes in radiative forcings will instantaneously affect local land and sea-surface temperatures, and these changes may operate on and feed back to the atmosphere on longer (daily to decadal) time scales. The oceans are particularly essential in driving the hydrological cycle (e.g. Mitchell, 1983). Sea surface temperatures (SSTs) are strongly coupled to both global land temperatures (e.g. Hoerling et al., 2008; Compo and Sardeshmukh, 2009) and precipitation (e.g. Koster and Suarez, 1995). Many modelling studies have focussed on the climatic response of the fully coupled system to changing carbon dioxide $\left(\mathrm{CO}_{2}\right)$ and aerosol concentrations, but only few examine the transient climatic response to time varying emissions of pollutants. In our paper, we use an atmospheric general circulation model (GCM) forced with prescribed SSTs, to quantify the transient response of the hydrological cycle to changing climate forcings in the period 1870-2005. 
Table 1. Summary of the different simulations. All the simulations cover the period 1870 to 2005 and are forced with time-varying greenhouse gas concentrations since 1870 .

\begin{tabular}{|c|c|c|c|}
\hline $\begin{array}{l}\text { Name of } \\
\text { ensemblemean }\end{array}$ & $\begin{array}{l}\text { Number of } \\
\text { experiments }\end{array}$ & SSTs & $\begin{array}{l}\text { Aerosol } \\
\text { emissions }\end{array}$ \\
\hline CTRL & 14 & Time-varying since 1870 & Time-varying since 1870 \\
\hline AEC & 4 & Time-varying since 1870 & Constant to 1870 value \\
\hline SSTC & 6 & Climatology averaged over $1871-1900$ & Time-varying since 1870 \\
\hline AESSTC & 3 & Climatology averaged over $1871-1900$ & Constant to 1870 value \\
\hline
\end{tabular}

The layout of the paper is as follows: Sect. 2 describes the methodology, Sect. 3 shows the results, and Sects. 4 and 5 discusses and concludes the study, respectively.

\section{Methodology}

In this section, we first explain the model set up and experiments (Sect. 2.1), we then show the evolution of the main climate forcings since 1870 (Sect. 2.2), and finally we describe the observational datasets used to validate our simulations (Sect. 2.3).

\subsection{Model set up and experimental design}

We perform climate simulations using the fifth generation of the atmospheric GCM, ECHAM (Roeckner et al., 2003). The basic prognostic variables, vorticity, divergence, temperature and surface pressure are represented by spherical harmonics with triangular truncation, in our case at wave number 42 (T42), which implies a horizontal grid spacing of approximately 2.8 degree. Non-linear processes and physical parameterization are solved on a corresponding Gaussian grid. Tracers are advected using the scheme by Lin and Rood (1996). In the vertical, 19 hybrid sigma-pressure levels are used, with the uppermost level at $10 \mathrm{hPa}$ (Roeckner et al., 2003). Since direct and indirect aerosol effects significantly affect the global temperature and precipitation (e.g. Ramanathan et al., 2001; Stier et al., 2006), we use a version of ECHAM5 that is coupled to a fully interactive aerosol module, the Hamburg Aerosol Model (HAM) (Stier et al., 2005). This module predicts the evolution of microphysically interacting internally and externally mixed aerosol populations. The major global aerosol categories, sulphate, black carbon (BC), particulate organic matter (POM), sea salt and mineral dust are included (Stier et al., 2005).

Hagemann et al. (2006) investigated the impact of model resolution on the hydrological cycle with ECHAM5 for the time period 1978-1999. They found that increasing the vertical resolution is more beneficial than increasing the horizontal resolution due to the improved moisture transport. They used horizontal resolutions going from T21 to T106, vertical resolutions going from 19 to 31 atmospheric layers, and forced ECHAM5 with prescribed SSTs and sea-ice dataset specifically constructed for the AMIP experiments by the NOAA Climate Analysis Centre (Gates, 1992).

In our study, we use ECHAM5-HAM at resolution T42 for the time period 1870-2005, and conduct a series of experiments driven by prescribed SSTs and accounting for different atmospheric forcings. The forcings used include the time varying monthly mean of the total solar irradiance (TSI) (Solanki and Krivova, 2003), time varying annually stratospheric optical depth due to aerosols from explosive volcanoes (Sato et al., 1993), and time varying annual mean of greenhouse gas concentrations taken from observations until 2000 and from the Intergovernmental Panel on Climate Change (IPCC) A1B scenario for 2001-2005 $\left(\mathrm{CO}_{2}\right.$, methane, nitrous oxide, ozone and chlorofluorocarbons). Emissions of sulphur dioxide $\left(\mathrm{SO}_{2}\right), \mathrm{BC}$ and $\mathrm{POM}$ are taken from the Japanese National Institute for Environmental Sciences (NIES) (Roeckner et al., 2006; Stier et al., 2006; Nozawa et al., 2007). They include geographically resolved time varying monthly mean emissions from wildfires, agricultural burning and domestic fuel-wood consumption, as well as time varying annual mean emissions from fossil fuel consumption. To reduce the source of uncertainty coming from atmosphere-ocean coupling, we force our model with monthly mean observed SSTs and sea-ice concentrations, using gridded data from Rayner et al. (2003). It was assembled by the Hadley Centre for Climatic Prediction and Research and consists of monthly observed sea ice and SSTs from 1870 to present. It covers the global sea surface at 1 degree resolution, and uses a two-stage reduced-space optimal interpolation procedure, followed by superposition of quality-improved gridded observations onto the reconstructions to restore local detail. SSTs near sea ice are estimated using statistical relationships between SST and sea ice concentration (Rayner et al., 2003).

We perform twenty-seven transient experiments, listed in Table 1. All the experiments run from 1870 to present and use a spin-up time ranging from several months to several years. The twenty-seven experiments are divided into four ensembles: Fourteen simulations correspond to the control runs (referred to as CTRL, "all forcings run"), for which all the forcings are time varying (e.g. TSI, greenhouse gases, aerosols and SSTs), four simulations are identical to CTRL except that aerosol emissions (anthropogenic and natural) are 
held constant at their 1870 level (referred to as AEC), six simulations are identical to CTRL except that SSTs are held constant at their 1871-1900 climatological values (referred to as SSTC), and three experiments are identical to CTRL except that both, SSTs and aerosol emissions (anthropogenic and natural) are held constant (referred to as AESSTC). Note that in AESSTC, the only remaining forcings expected to affect the climate at decadal scale are the greenhouse gases and the TSI. AESSTC can therefore be used to evaluate the impact of these two forcings, knowing that the TSI cannot be a dominant factor influencing the climate after 1970 (Solanki and Krivova, 2003).

To suppress the "noise" from individual simulations and assess their natural variability, we calculate ensemble means and quantify their uncertainties via the computation of their standard deviation (assuming a normal distribution). We also carried out tests with different ensemble sizes (not shown), and use at least three members ensembles to estimate the ensemble spread. In our sensitivity studies, we do not separate the explosive volcanic aerosols from other aerosols (e.g. anthropogenic), since no significant difference was found, in the $11 \mathrm{yr}$ running means, between the global land temperature and precipitation anomalies simulated with, and without explosive volcanic emissions (not shown). This lack of differentiation may come from the prescribed SSTs. Therefore, "aerosol emissions" in our paper always refer to anthropogenic and natural (including explosive volcanic) aerosols.

\subsection{Evolution of the main climate forcings since $\mathbf{1 8 7 0}$}

Figure 1a-c shows the global annual mean emissions of $\mathrm{SO}_{2}$, $\mathrm{BC}$ and $\mathrm{OC}$ (from NIES), Fig. 1d shows the stratospheric aerosol optical depth due to explosive volcanoes (Sato et al., 1993), and Fig. 1e shows the global seasonal SST anomalies relative to the 1870-2000 mean (Rayner et al., 2003).

Aerosol emissions from fossil fuel (Fig. 1a-c, red curves) increase slightly from 1870 to 1910 , stabilize until 1930, increase strongly until 1990 and then stabilize. On the other hand, aerosol emissions from biofuel (black curves) and wildfires (green curves), together with the greenhouse gas concentrations (not shown), increase slightly from 1870 to the 1950s and strongly after this date. Emissions of $\mathrm{SO}_{2}$ from fossil fuel (Fig. 1a, red curve) and BC and OC from wildfires (Fig. 1b-c, green curve) exhibit the strongest increase since 1870. In addition, large volcanoes are very active between 1870 and 1920 as well as between 1960 and 2000, but almost absent between 1920 and 1960 (Fig. 1d). Finally, global SST anomalies are relatively stable from 1870 to 1910 , increase until 1940, stabilize until 1970 and then increase (Fig. 1e).

\subsection{Observational data for temperature and precipitation}

To make full use of our results, we validate our simulations against observed temperature and precipitation datasets cov-
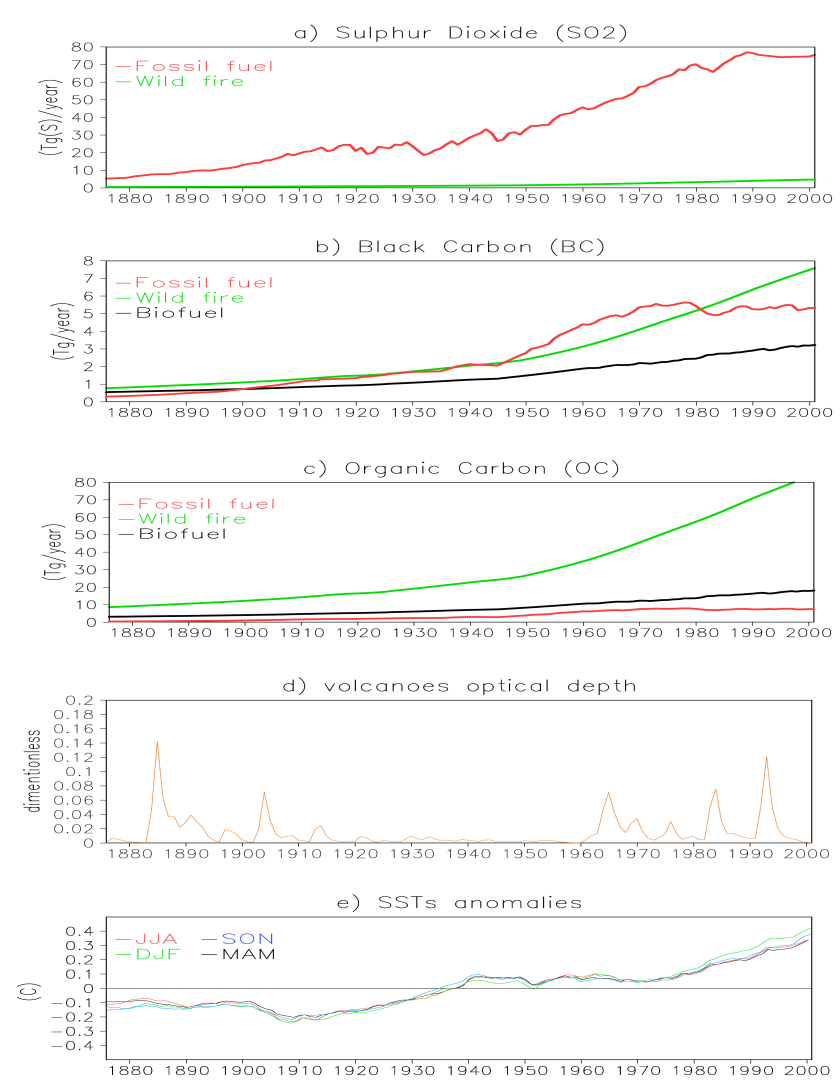

Fig. 1. Global annual time series of anthropogenic aerosol emissions (a-c) and stratospheric optical depth due to explosive volcanoes (d), and global seasonal time series of SST anomalies shown as $11 \mathrm{yr}$ running means (e). The SST anomalies are in ${ }^{\circ} \mathrm{C}$ and correspond to the SST global mean value for each year, minus the global mean of the reference period 1870-2000.

ering the globe since 1870 . Because historic observational data are scarce over the oceans, we limit our analysis to the land.

We first look at temperature. At least four datasets cover the global land temperature since 1880 (Hansen et al., 2001; Lugina et al., 2005; Smith and Reynolds, 2005; Brohan et al., 2006), one of them even starts in 1850 (Brohan et al., 2006). Since the global land annual means of these four datasets are in good agreement since 1880 (IPCC AR4, 2007), we validate our simulated temperatures against one single dataset, "CRUTEM3", starting in 1850 (Brohan et al., 2006). It has been assembled by the Climate Research Unit of the University of East Anglia (CRU) and consists of monthly observed two meters air temperatures from 1850 to present. It is based on 4349 stations and covers the global land surface at 5 degree resolution. It uses an interpolation method such that each grid box value is the mean of all available station anomaly values excluding the station outliers in excess of five standard deviations. Missing values are not spatially infilled and most gaps are found in the tropics and the Southern 
(particularly Antarctica), as well as during the 19th century and the two world wars (Brohan et al., 2006). When comparing observed against simulated temperatures, we change the grid of the simulated temperatures each year according to the data coverage.

We validate our simulated precipitation against two observational datasets. The first one, "CRU TS 2.1" (Mitchell and Jones, 2005), has been assembled by the CRU, and consists of monthly observed precipitation going from 1901 to 2002. It covers the global land surface at 0.5 degree resolution and includes oceanic islands but excludes Antarctica. The interpolation is done directly from station observations and uses the angular distance-weighting method. Because this dataset has not been corrected for gauge biases, it may undercatch solid precipitation in colder areas (New et al., 2000). Note that for the two datasets assembled by the CRU, namely "CRUTEM3" and "CRU TS 2.1", the station data values are first transformed into anomalies relative to a standard normal period prior to interpolation (New et al., 2001). The second precipitation dataset, "GHCN" (Peterson and Vose, 1997), has been assembled by the National Oceanic and Atmospheric Administration (NOAA) and consists of monthly observed precipitation calculated from the "GHCN V2" dataset going from 1900 to 2009. It comprises stations with varying temporal coverage going from 5500 in 1900 to 16500 in 1966, and covers the global land surface at 5 degree resolution (New et al., 2001).

Although no quantified uncertainties are given with these precipitation datasets, most uncertainties, due to poor spatial coverage, are located in the high latitudes, arid regions and parts of the tropics (New et al., 2001). Additional uncertainties can come from errors and biases in the gauge measurements as well as inhomogeneity arising from several sources (New et al., 2000 and 2001). Finally, since both precipitation datasets ("CRU" and "GHCN") have been spatially infilled by interpolation (Mitchell and Jones, 2005; New et al., 2001), there is no need to change the grid of the simulated precipitation according to the data coverage as it was done for temperature.

\section{Results}

This section first evaluates the capacity of ECHAM5-HAM to reproduce the observations (Sect. 3.1). It then describes the results from the sensitivity experiments (Sect. 3.2). All the time series are shown as $11 \mathrm{yr}$ running mean anomalies, with a reference period varying according to the analysis. We first calculate the anomalies, then the global means, and finally the running means.

\subsection{Global scale assessment of the model}

Observed (dashed curves) and simulated (CTRL, solid curves) global land temperature anomalies are shown in
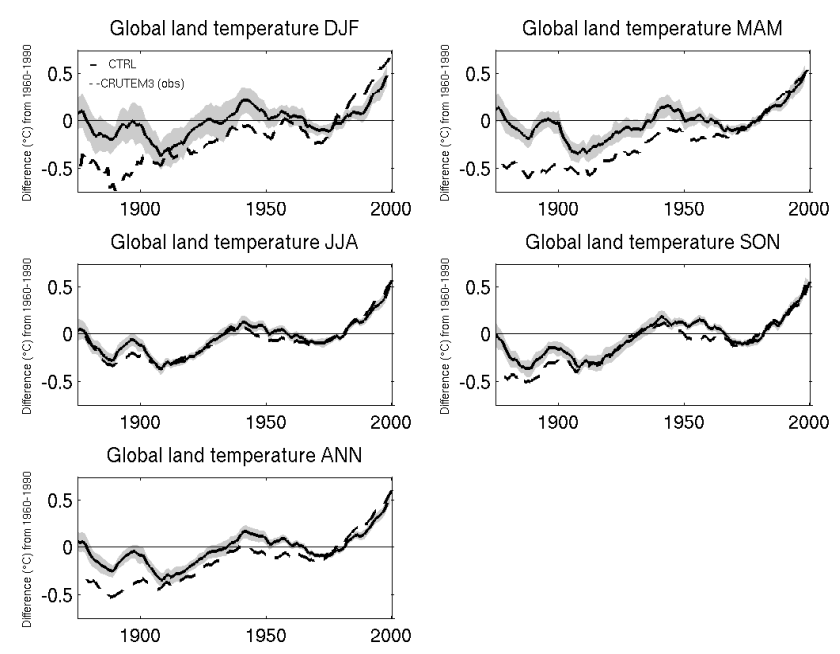

Fig. 2. Simulated (CTRL, solid) and observed (CRUTEM3, dashed) annual and seasonal global land temperature anomalies $\left({ }^{\circ} \mathrm{C}\right)$, relative to the 1960-1990 mean, shown as $11 \mathrm{yr}$ running means. Gray shaded area corresponds to the \pm 1 sigma spread of the ensemble CTRL.

Fig. 2, relative to the $1960-1990$ mean. Note that whereas observed temperatures correspond to the two meters temperatures, simulated temperatures refer to the surface "skin" temperatures. Qualitatively, simulated and observed anomalies are in good agreement since 1870, particularly in the June-July-August (JJA) and September-October-November (SON) averages (Fig. 2). In line with the IPCC AR4 (2007), global land annual anomalies show two warming periods of about $0.5^{\circ} \mathrm{C}$ each, one from 1910 to 1940 , and a second one after about 1980. According to Fig. 2, this is the case in all seasons.

Two warm biases occur in the global land annual averages: One in the late nineteenth century $\left(0.2^{\circ} \mathrm{C}\right.$ on average $)$ and a second one in the $1940 \mathrm{~s}$ and $1950 \mathrm{~s}\left(0.1^{\circ} \mathrm{C}\right.$ on average). Both are particularly pronounced in the DecemberJanuary-February (DJF) and March-April-May (MAM) averages. Figure 3 shows that the warm bias in the late nineteenth century is mostly located in Siberia. Interior of continents such as Siberia are more likely to have biases in our experiments since they are the least constrained by SSTs. On the other hand, the warm bias in the 1940s and 1950s falls into a period with a general underestimation of SSTs due to changes in observational practice (Thompson et al., 2008). The cold biases contained in the driving SSTs should thus trigger cold biases in the simulated land temperatures, which is opposite to our results (Fig. 2). This means that the simulated warm bias in the 1940s and 1950s might actually be somewhat larger than indicated in Fig. 2. 

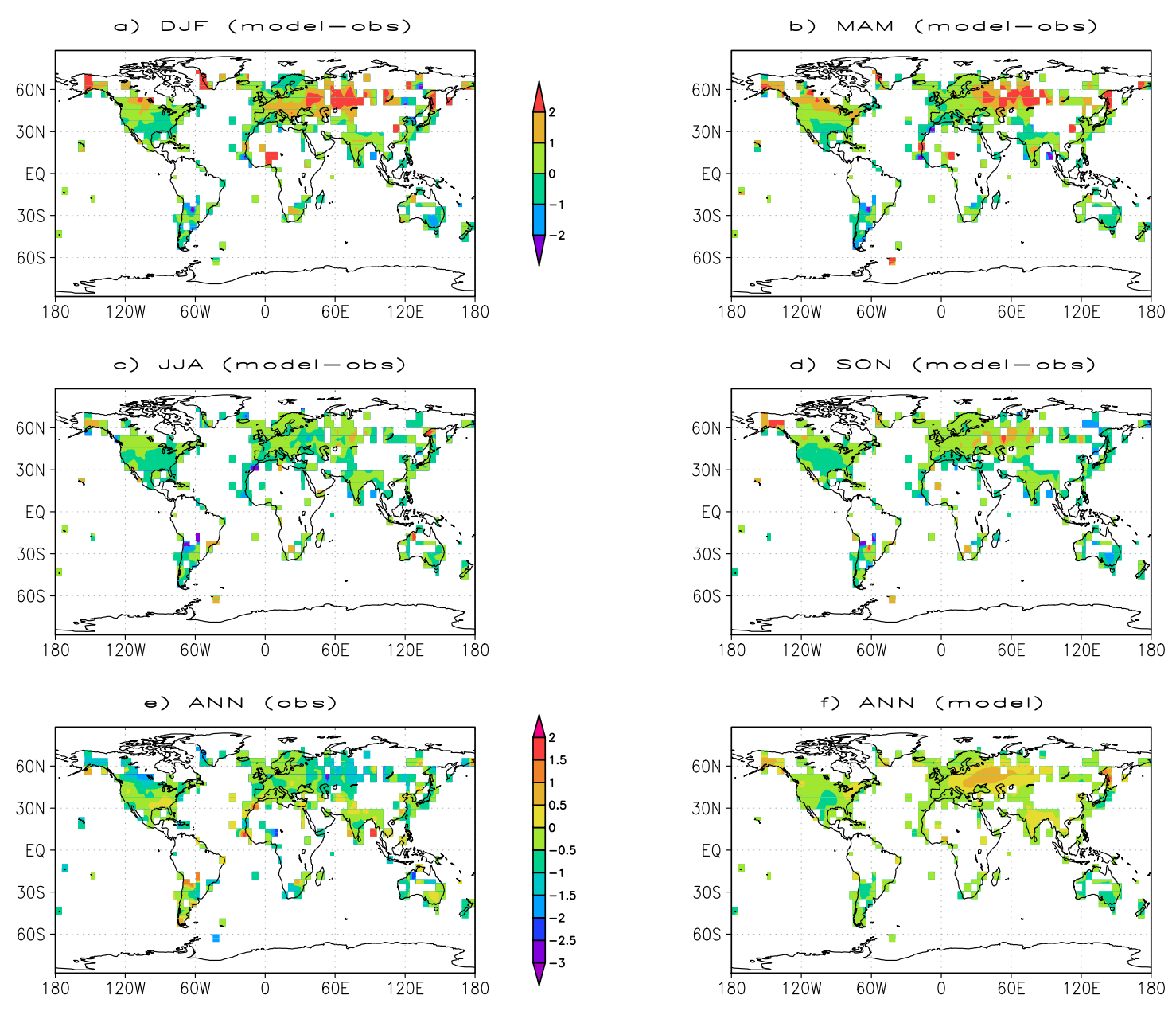

Fig. 3. Maps of seasonal land temperature biases $\left({ }^{\circ} \mathrm{C}\right)$ averaged over the time period 1890-1900 (a-d). The maps correspond to the difference between the temperature anomalies from the CTRL ensemble mean and from observations (CRUTEM3), remapped on a T42 grid. The annual temperature maps $\left({ }^{\circ} \mathrm{C}\right)$ are shown as observed (e) and simulated (f) anomalies, averaged over the time period 1890-1900. Here, the reference period 1960-1990 has been used.

The global land precipitation anomalies relative to the 1901-2000 mean are shown in Fig. 4. Despite a wet bias in the 1930s and a dry bias in the 1970s, both located in China and in Northern South America (not shown), simulated (solid curves) and observed (dashed curves) global land precipitation anomalies are in reasonable agreement since 1901 (Fig. 4): Both exhibit an increase during the first half of the 20th century, a decline until the early 1990s and then recover (New et al., 2001; IPCC AR4, 2007). However, the magnitude and timing of the associated decadal variations is not well captured. Note that the centennial trends are relatively small compared to decadal variations.

Figure $5 \mathrm{~b}-\mathrm{c}$ shows the simulated (solid curves) and observed ("CRU", dashed curves) land precipitation anomalies relative to the 1901-2000 mean with yearly resolution. In the tropics, interannual and decadal variations are surprisingly well reproduced (Fig. 5c), while on a global scale there are considerable discrepancies (Fig. 5b). In addition, Fig. 5b-c shows that observed and simulated land precipitation anomalies decrease after large tropical volcanic eruptions (blue vertical lines) as well as during El Nino events (green vertical lines), and increase during La Nina events (magenta vertical lines). These atmospheric responses, more pronounced in the tropics (Fig. 5c), are in line with previous studies (Gu et al., 2007; Trenberth and Dai, 2007), and suggest, in agreement with Hagemann et al. (2006), that ECHAM5-HAM produces a realistic response of land precipitation to changes in external forcings and SSTs.

\subsection{Global scale sensitivity of the model to external forcing}

Figures 6 and 7 show the global land temperature and precipitation anomalies, respectively, relative to the 1870-1880 mean. Both figures show the ensemble means simulated in CTRL (black curve), SSTC (blue curve), AEC (red curve) and AESSTC (green curve), (see Table 1 and Sect. 2.1). 


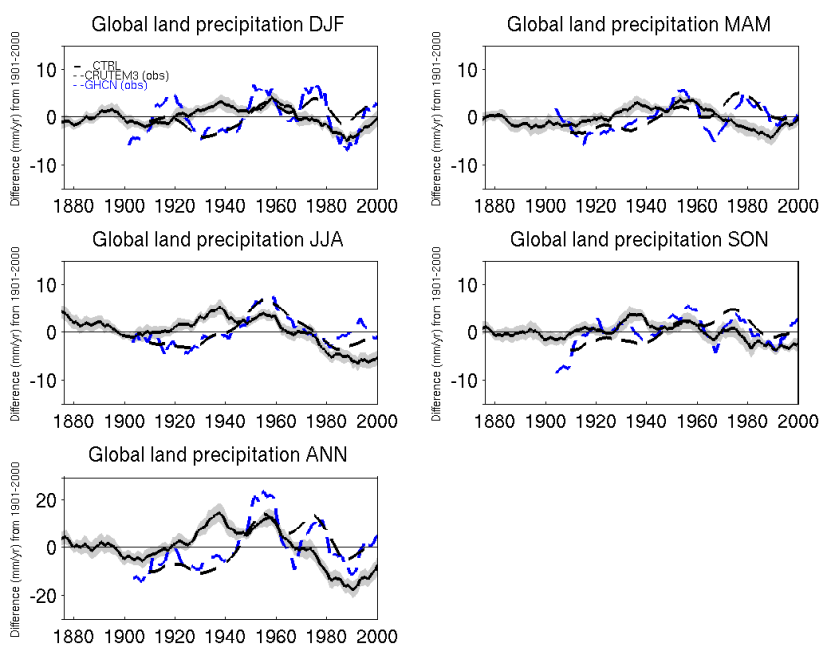

Fig. 4. Simulated (CTRL, solid) and observed (CRU, black dashed; GHCN, blue dashed) annual and seasonal global land precipitation anomalies ( $\mathrm{mm} \mathrm{season}{ }^{-1}$ and $\mathrm{mm} \mathrm{yr}^{-1}$, respectively), relative to the 1901-2000 mean, shown as 11 yr running means. Gray shaded area corresponds to the \pm 1 sigma spread of the ensemble CTRL.
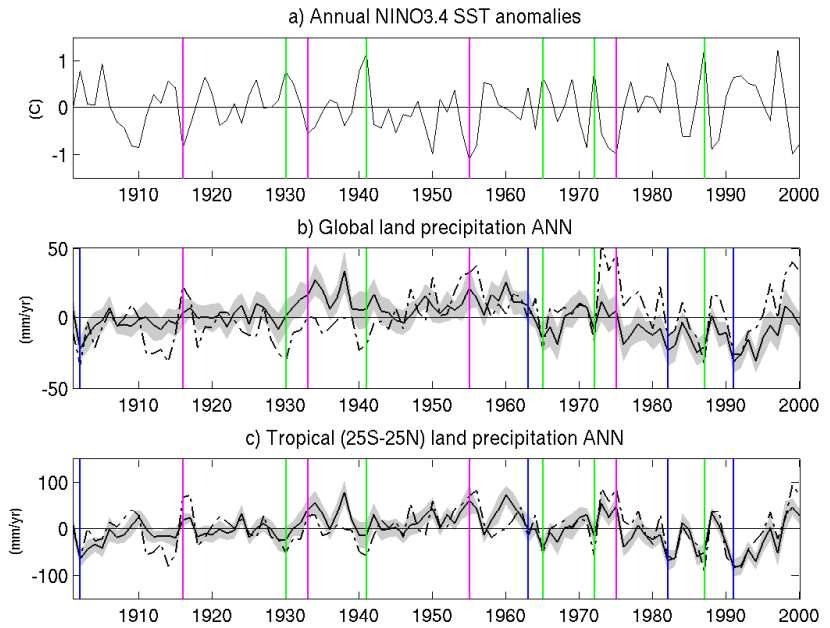

Fig. 5. Annual NINO 3.4 index anomalies calculated from observed SSTs (Rayner et al., 2003) (a). Simulated (CTRL, solid curves) and observed (CRU, dashed curves) global (a) and tropical ((b) $25^{\circ} \mathrm{S}-25^{\circ} \mathrm{N}$ ) land precipitation anomalies, plotted with yearly resolution. Here, the reference period 1901-2000 has been used. El Nino (green lines), La Nina (magenta lines) and large tropical volcanic eruptions (blue lines) years.

According to Figs. 6 and 7, the different ensemble means, corresponding to different forcings, significantly depart from each other. Since at least qualitatively, annual and seasonal global land temperature and precipitation anomalies are similar to each other, we focus our discussion on annual means only.
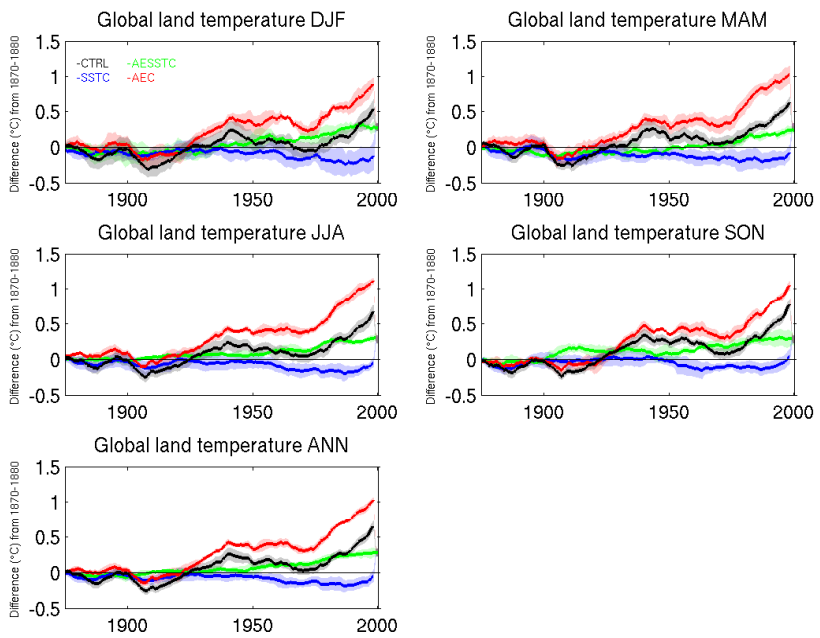

Fig. 6. Simulated annual and seasonal global land temperature anomalies $\left({ }^{\circ} \mathrm{C}\right)$, relative to the $1870-1880$ mean, shown as $11 \mathrm{yr}$ running means. Shaded areas correspond to the \pm 1 sigma spread of each ensemble.

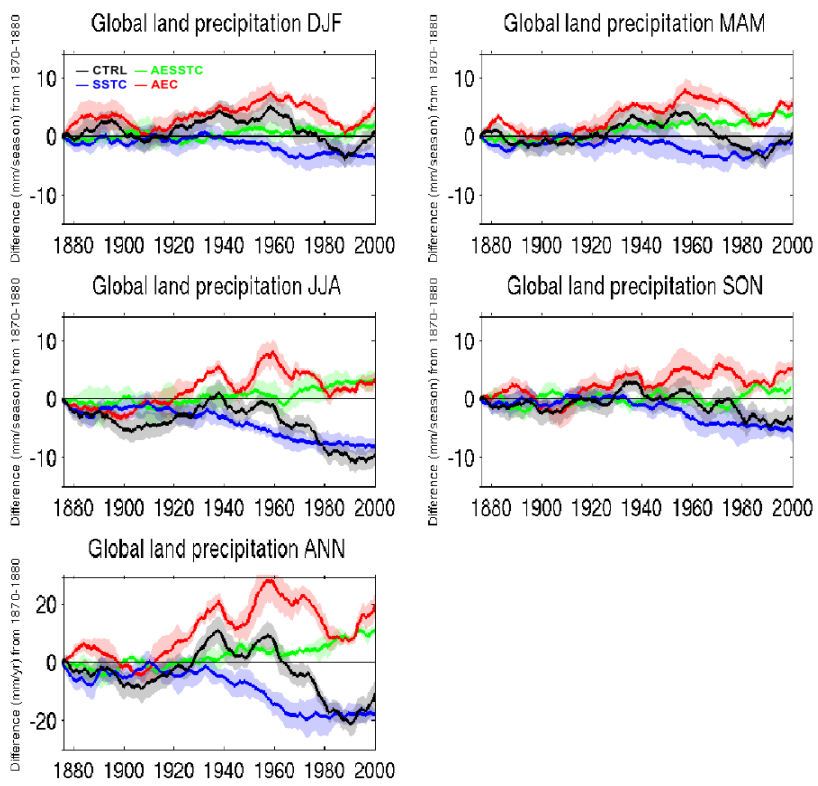

Fig. 7. Simulated annual and seasonal global land precipitation anomalies (mm season ${ }^{-1}$ and $\mathrm{mm} \mathrm{yr}^{-1}$, respectively), relative to the $1870-1880$ mean, shown as $11 \mathrm{yr}$ running means. Shaded areas correspond to the \pm 1 sigma spread of each ensemble.

According to Fig. 6, the global land temperature anomalies simulated in CTRL (black curve) show a clear decadal variability since 1870 , which is suppressed in the anomalies simulated with climatological SSTs (SSTC and AESSTC): Not present in the SSTC and AESSTC simulations are in particular, the two temperature increases from 1910 to 1940 and 1980 to 2000. Instead, the anomalies simulated in SSTC 
(blue curve) are constant until 1950, decrease by about $0.2^{\circ} \mathrm{C}$ from 1950 to 1990 and then recover, whereas the anomalies simulated in AESSTC (green curve) are constant until about 1950 and increase by about $0.25^{\circ} \mathrm{C}$ from 1950 to 2000 . In addition, although the anomalies simulated in AEC (red curve) show a similar decadal variability than the ones simulated in CTRL (black curve), they exhibit a larger trend after about 1930 (up to $0.4{ }^{\circ} \mathrm{C}$ warmer in 2000).

According to Fig. 7, the global land precipitation anomalies simulated in CTRL (black curve) also show a clear decadal variability since 1870 , which is suppressed in the anomalies simulated with climatological SSTs (SSTC and AESSTC): Not present in the SSTC and AESSTC simulations are in particular, the two precipitation maxima in the late 1930s and late 1950s. Instead, the anomalies simulated in SSTC (blue curve) are constant until 1930, decrease by about $20 \mathrm{~mm} \mathrm{yr}^{-1}$ between 1930 and 1970 and then stabilize, whereas the anomalies simulated in AESSTC (green curve) are constant until about 1930 and increase by about $10 \mathrm{~mm} \mathrm{yr}^{-1}$ from 1930 to 2000 . In addition, although the anomalies simulated in AEC (red curve) show a similar decadal variability than the ones simulated in CTRL (black curve), the former exhibit almost no trend after 1930, whereas after this date, the latter decrease by about $10 \mathrm{~mm} \mathrm{yr}^{-1}$. This implies that the global land precipitation centennial trend (1900-2000) is negative with transient aerosol emissions (CTRL and SSTC) but positive with constant aerosol emissions (AEC and AESSTC).

\section{Discussion}

In the following section, we investigate the physical processes behind these sensitivities, focussing on the hydrological cycle. Section 4.1 explains where, at global scale, the water falling on land comes from. Sections 4.2 and 4.3 discuss the sensitivity of this water cycle to SSTs and external forcings, respectively. All the time series are shown as $11 \mathrm{yr}$ running means.

\subsection{Origin of water in the global land precipitation}

The global land precipitation has two sources: The land evaporation and the advection of moisture from the oceans. According to Fig. 8a (black curve), the global land surfaces evaporate about $500 \mathrm{~mm}$ of water per year. Because the global land precipitation amounts to about $760 \mathrm{~mm} \mathrm{yr}^{-1}$ (not shown), we conclude, in agreement with previous studies (e.g. Wild et al., 2008), that at least $35 \%\left(260 \mathrm{~mm} \mathrm{yr}^{-1}\right)$ of the global land precipitation must come from the oceans (Fig. 8b, black curve). According to Van der Ent et al. 2010 however, the water recycling on land is about $57 \%$. Therefore, out of the $65 \%$ global land precipitation, only $57 \%$ falls back on land. This implies that about $40 \%$ of the global land precipitation actually comes from land evaporation and
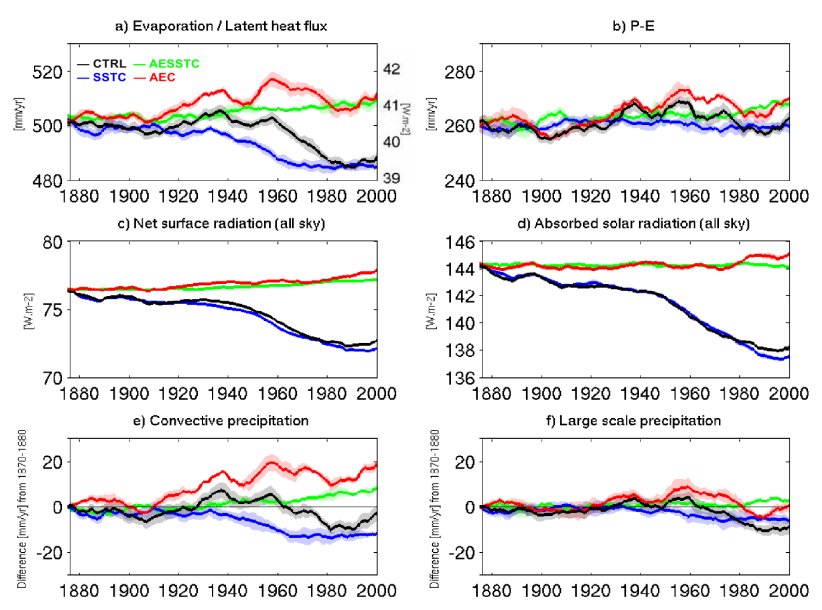

Fig. 8. Simulated annual global land absolute values of evaporation (left hand side axis, $\mathrm{mm} \mathrm{yr}^{-1}$ ) and latent heat flux (right hand side axis, $\mathrm{W} \mathrm{m}^{-2}$ ) (a), precipitation minus evaporation (P-E, $\left.\mathrm{mm} \mathrm{yr}^{-1}\right)(\mathbf{b})$, net surface radiation all sky $\left(\mathrm{W} \mathrm{m}^{-2}\right)$ (c) and absorbed solar radiation all sky $\left(\mathrm{W} \mathrm{m}^{-2}\right)(\mathbf{d})$, as well as anomalies of convective (e) and large scale precipitation (f) $\left(\mathrm{mm} \mathrm{yr}^{-1}\right.$; ref: 1870-1880). All the time series are shown as $11 \mathrm{yr}$ running means. Shaded areas correspond to the \pm 1 sigma spread of each ensemble.

thus, $60 \%$ is advected from the oceans. Nevertheless, our results show that in the $11 \mathrm{yr}$ running mean time series, the global land precipitation trend $\left(-0.92\right.$ mm decade $\left.^{-1}\right)$ and variability are more highly correlated with the trend $\left(-0.77 \mathrm{mmdecade}^{-1}\right)$ and variability of the global land evaporation $\left(r^{2}=0.81\right)$, than with the ones of global oceanic evaporation (trend: $-0.15 \mathrm{~mm} \mathrm{decade}^{-1}, r^{2}=0.36$ ).

Over the oceans, our modelling framework implies that the evaporation directly depends on the prescribed SSTs. Over land however, evaporation depends on the energy balance (governed by the net surface radiation) and on the air moisture holding capacity (governed by the Clausius-Clapeyron relation) (e.g. Penman, 1950; Hartmann, 1994). Note that changes in land evapotranspiration will in addition depend upon changes in the availability of water (soil moisture). According to our $11 \mathrm{yr}$ running mean time series, about $76 \%$ of the global land evaporation (Fig 8a, black curve) is directly explained by the global land net surface radiation (Fig. 8c, black curve, $r^{2}=0.76$ ). This implies that changes in air moisture holding capacity and/or soil moisture, both being also under the influence of the net surface radiation, explain the remaining $24 \%$.

\subsection{Role of SSTs}

Our results show that since 1870 , SSTs determine the decadal and interannual variabilities of the global land temperature and precipitation (Sect. 3.2): Compared with fully transient simulations, simulations with climatological 


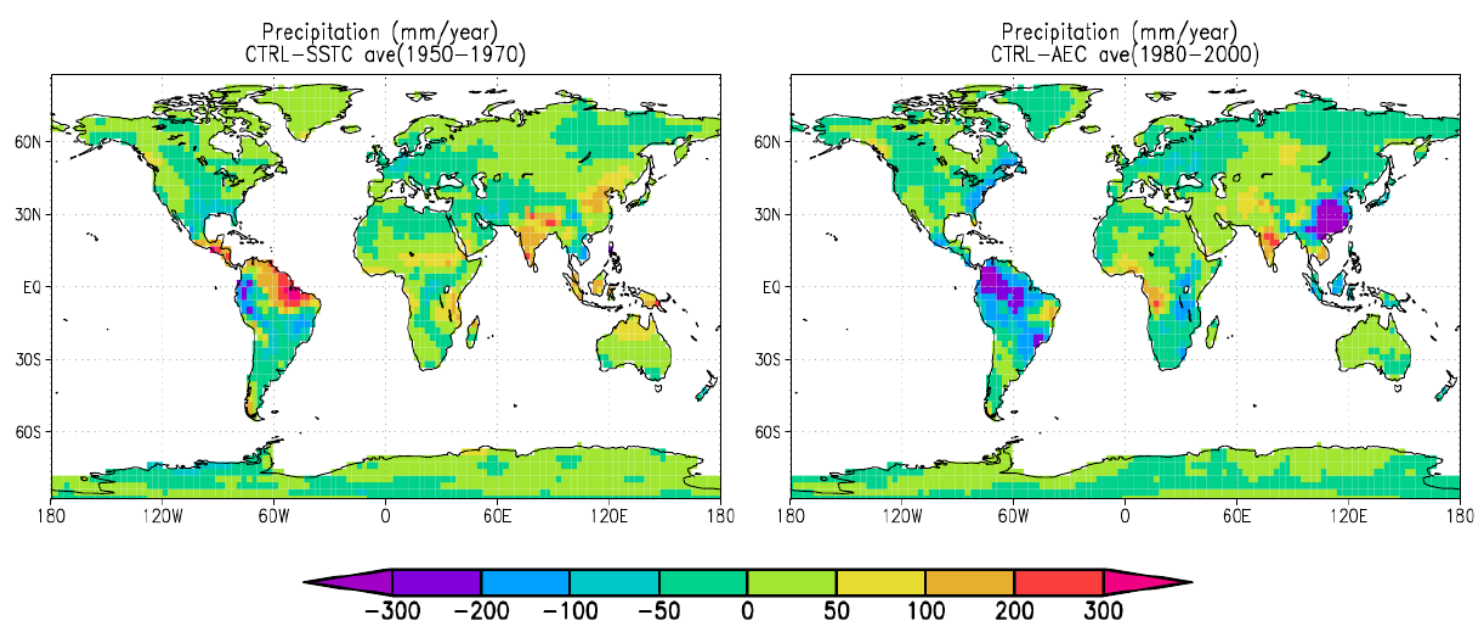

Fig. 9. Maps of annual land precipitation $\left(\mathrm{mm} \mathrm{yr}^{-1}\right)$ differences between the anomalies from the CTRL and the SSTC ensemble means, averaged over the time period 1960-1970 (a), and between the anomalies from the CTRL and the AEC ensemble means, averaged over the time period 1980-2000 (b). Here, the reference period 1870-1880 has been used.

SSTs show hardly any decadal variability in these variables (Figs. 6 and 7).

On the one hand, the high correlation coefficient between the $11 \mathrm{yr}$ running mean time series of the global annual SSTs and land temperatures simulated in CTRL $\left(r^{2}=0.85\right)$, indicates, in line with previous studies (e.g. Hoerling et al., 2008; Compo and Sardeshmukh, 2009; Findell et al., 2009), that the two variables are strongly coupled: Warmer SSTs increase land temperatures primarily via moistening and warming of the air over land, which then increase the downward longwave radiation at the surface (Compo and Sardeshmukh, 2009).

On the other hand, while we see that the decadal variation of the global land precipitation is determined by the SSTs (Fig. 7), the relation is not trivial: The red curve (AEC) from Fig. 7 shows that SSTs increase the global land precipitation before 1960, decrease it between 1960 and 1990 and increase it after 1990. However, Fig. 1e shows that global SSTs increase from 1910 to 1940 , stabilize from 1940 to 1980 and increase after 1980. In line with previous studies (e.g. Gu et al., 2007; Trenberth and Dai, 2007), Fig. 5a-b suggests that El Nino and La Nina events affect the global land precipitation, a negative (positive) El Nino Southern Oscillation (ENSO) index being associated with high (low) global land precipitation. The NINO 3.4 index shown in Fig. 5a is reconstructed from observed SSTs (Rayner et al., 2003) and defined as the average $\left(5^{\circ} \mathrm{S}-5^{\circ} \mathrm{N} ; 170-120^{\circ} \mathrm{W}\right)$ of Pacific SST anomalies (e.g. Trenberth, 1997). Since the ENSO index is negative between 1940 and 1960 and increases after 1960 (Fig. 5a), it provides some evidence that after 1960, the increasing frequency of El Nino events may have reduced the global land precipitation via their associated changes in atmospheric circulation. Note that changes in air moisture holding capacity may also influence the impact of SSTs on global land precipitation. Consistent with the above argumentation, Fig. 9a shows that SSTs affect mostly the tropical precipitation, especially in the regions strongly related with ENSO (South-East Asia, India and South America). In addition, further analyses (not shown) show that the decadal and interannual variabilities of the global land precipitation are dominated by the tropics $\left(25^{\circ} \mathrm{S}-25^{\circ} \mathrm{N}\right)$.

\subsection{Role of aerosols and greenhouse gases}

Because in our simulations (prescribed SSTs) the ocean cannot respond to the changing external forcings applied in the sensitivity experiments, the sensitivities discussed in the following section refer to atmospheric processes only.

We first compare the ensemble means from CTRL (black curves) and AEC (red curves), which differ from each other only by their aerosol emissions. According to Fig. 8d, at global land scale, increasing aerosol emissions decrease the solar radiation absorbed at the surface, after about 1930, by up to $6.2 \mathrm{~W} \mathrm{~m}^{-2}$. In turn, this decreases the net surface radiation by up to $5.4 \mathrm{~W} \mathrm{~m}^{-2}$ (Fig. 8c), the latent heat flux by up to $2 \mathrm{~W} \mathrm{~m}^{-2}$ (equivalent to about $23 \mathrm{~mm} \mathrm{yr}^{-1}$ in evaporation, Fig. 8a), and the P-E by up to $10 \mathrm{~mm} \mathrm{yr}^{-1}$ (Fig. 8b). The reduced land evaporation combined with the reduced advection of moisture from the oceans thus decreases the global land precipitation, after about 1930 , by up to $30 \mathrm{~mm} \mathrm{yr}^{-1}$ (Fig. 7). About two third of this global land precipitation decrease is in the form of convection (Fig. 8e-f), mostly located in Northern South America and in China (Fig. 9b). In addition, especially absorbing aerosols higher up in the troposphere can reduce the convection via their impact on stability (Koch and Del Genio, 2010). Finally, indirect aerosol effects are also expected to decrease the global land precipitation (Ramanathan et al., 2001). However, even though the associated processes are taken into account in our simulations, our 
experimental set up does not allow to quantify their impacts separately from the other aerosols impacts.

We now look at the AESSTC ensemble mean (green curves), which corresponds to the simulations where greenhouse gases and TSI constitute the only transient forcings. According to Fig. 8c, at global land scale, increasing the greenhouse gas concentrations increases the net surface radiation, after about 1950 , by up to $1 \mathrm{~W} \mathrm{~m}^{-2}$, which increases the latent heat flux by up to $0.4 \mathrm{~W} \mathrm{~m}^{-2}$ (equivalent to about $5 \mathrm{~mm} \mathrm{yr}^{-1}$ of evaporation) (Fig. 8a) and the P-E by up $5 \mathrm{~mm} \mathrm{yr}^{-1}$ (Fig. 8b). The enhanced land evaporation combined with the enhanced advection of moisture from the oceans thus increase the global land precipitation, after about 1950, by up to $10 \mathrm{~mm} \mathrm{yr}^{-1}$ (Fig. 7). About two third of this global land precipitation increase is in the form of convection (Fig. 8e-f).

The combined atmosphere-only effect of aerosols and greenhouse gases is apparent in the SSTC ensemble mean (blue curves). Our results suggest, in agreement with previous studies (e.g. Wild et al., 2007; Wild and Liepert, 2010), that the aerosol effects dominate between about 1950 and 1970 , as both, global land temperature and precipitation decrease during this time period (Figs. 6 and 7, blue curves). After about 1970 however, the greenhouse gases start to dominate, as there is no further decrease in either temperature or precipitation.

Finally, our results show that since 1870, increasing aerosols emissions decreases the global oceanic net surface radiation by up to $3 \mathrm{~W} \mathrm{~m}^{-2}$ (not shown). In the real world, this is expected to cool the SSTs, which is in turn expected to decrease the global land temperature and precipitation. Because this process cannot be simulated in our modelling framework (prescribed SSTs), we suggest that the atmosphere-only sensitivities discussed in this section are rather minimum estimates, and could be larger if the full system (including the ocean feedback) was taken into account. This also applies to the greenhouse gas concentrations response.

\section{Conclusions}

Our study shows that ECHAM5-HAM, forced with prescribed SSTs and transient greenhouse gas and aerosol emissions, is able to very satisfactorily reproduce the observed tropical land temperature and precipitation variations since the early 20th century, while it has substantial biases in terms of extratropical precipitation variations. Sensitivity studies show that in our framework, SSTs (encapsulating other forcings and internal variability) determine the decadal and interannual variabilities of the global land temperature and precipitation since 1870 , which is mostly due to the large impact of SSTs in the tropics $\left(25^{\circ} \mathrm{S}-25^{\circ} \mathrm{N}\right)$. In addition, we find that between about 1930 and 2005, the atmosphere-only response to increasing aerosol emissions is a reduction in global land temperature and precipitation by up to $0.4{ }^{\circ} \mathrm{C}$ and $30 \mathrm{~mm} \mathrm{yr}^{-1}$, respectively. Similarly, between about 1950 and 2005, the atmosphere-only response to increasing greenhouse gas concentrations is an increase in global land temperature and precipitation by up to $0.25^{\circ} \mathrm{C}$ and $10 \mathrm{~mm} \mathrm{yr}^{-1}$, respectively. Finally, in agreement with previous studies (e.g. Wild et al., 2007 and 2008; Wild and Liepert, 2010), we suggest that between about 1950 and 1970, aerosols have "masked" the greenhouse gas impact on the hydrological cycle.

Acknowledgements. The authors thank the MPI Hamburg for providing access to the ECHAM5-HAM code and colleagues at ETH Zürich who contributed to model development, in particular Ulrike Lohmann. This research has partly been supported by the NCCR Climate funded by the Swiss National Science Foundation. The simulations were done on the CRAY XT-5 at the Swiss National Supercomputing Centre (CSCS) in Manno, Switzerland.

Edited by: J. Quaas

\section{References}

Allen, M. R. and Ingram, W. J.: Constraints on future changes in climate and the hydrological cycle, Nature, 419, 224-232, 2002.

Boer, G. J.: Climate change and the regulation of the surface moisture and energy budgets, Clim. Dynam., 8, 225-239, 1993.

Brohan, P., Kennedy, J. J., Harris, I., Tett, S. F. B., and Jones, P. D.: Uncertainty estimates in regional and global observed temperature changes: A new data set from 1850, J. Geophys. Res., 111, 12106, doi:10.1029/2005JD006548, 2006.

Compo, G. P. and Sardeshmukh, P. D.: Oceanic influences on recent continental warming, Clim. Dynam., 32, 333-342, 2009.

Findell, K. L., Pitman, A. J., England, M. H., and Pegion, P. J.: Regional and global impacts of land-cover changes and sea-surface temperature anomalies, J. Climate, 22, 3248-3269, 2009.

Gates, W. L.: AMIP: The Atmospheric Model Intercomparison Project, B. Am. Meteorol. Soc., 73, 1962-1970, 1992.

Gu, G., Adler, R. F., Huffman, G. J., and Curtis, S.: Tropical Rainfall Variability on Interannual-to-Interdecadal and Longer Time Scales Derived from the GPCP Monthly Product, J. Climate, 20, 4033-4046, 2007.

Hagemann, S., Arpe, K., and Roeckner, E.: Evaluation of the Hydrological Cycle in the ECHAM5 Model, J. Climate, 19, 38103827, 2006.

Hansen, J., Ruedy, R., Sato, M., Imhoff, M. L., Lawrence, W. T., Easterling, D. R., Peterson T. C., and Karl, T. R.: A closer look at United States and global surface temperature change, J. Geophys. Res., 106, 23947-23963, 2001.

Hartmann, D. L.: Global Physical Climatology, International Geophysics Series, 56, edited by: Smowska, R. and Holton, J. R., Academic Press Limited, London, 1994.

Hoerling, M., Kumar, A., Eischeid, J., and Jha, B.: What is causing the variability in global mean land temperature?, Geophys. Res. Lett., 35, 23712, doi:10.1029/2008GL035984, 2008.

IPCC AR4: Contribution of Working Group I to the Fourth Assessment Report of the Intergovernmental Panel on Climate Change, edited by: Solomon, S., Qin, D., Manning, M., Chen, Z., Mar- 
quis, M., Averyt, K. B., Tignor, M., and Miller, H. L., Cambridge University Press, Cambridge, 2007.

Koch, D. and Del Genio, A. D.: Black carbon semi-direct effects on cloud cover: review and synthesis, Atmos. Chem. Phys., 10, 7685-7696, doi:10.5194/acp-10-7685-2010, 2010.

Koster, R. D. and Suarez, M. J.: Relative contributions of land and ocean processes to precipitation variability, J. Geophys. Res., 100, 13775-13790, 1995.

Liepert, B. G., Feichter, J., Lohmann, U., and Roeckner, E.: Can aerosols spin down the water cycle in a warmer and moisture world?, Geophys. Res. Lett., 31, 06207, doi:10.1029/2003GL019060, 2004.

Lin, S. J. and Rood, R. B.: Multidimentional Flux-Form SemiLagrangian Transport Scheme, Mon. Weather Rev., 124, 20462070, 1996.

Lugina, K. M., Groisman, P., Vinnikov, K. Ya., Koknaeva, V. V., and Speranskaya, N. A.: Monthly surface air temperature time series area-averaged over the 30-degree latitudinal belts of the globe, 1881-2005, in: Trends: A Compendium of Data on Global Change, Carbon Dioxide Information Analysis Center, Oak Ridge National Laboratory, US Department of Energy, Oak Ridge, Tenn., USA, doi:10.3334/CDIAC/cli.003, available at: http://cdiac.esd.ornl.gov/trends/temp/lugina/lugina.html, 2005.

Mitchell, J. F. B.: The seasonal response of a general circulation model to change in $\mathrm{CO}_{2}$ and sea temperatures, Quaternary Journal of Research for Meteorological Society, 109, 113-152, 1983.

Mitchell, T. D. and Jones, P. D.: An improved method of constructing a database of monthly climate observations and associated high resolution grids, Int. J. Climatol., 25, 693-712, 2005.

New, M., Hulme M., and Jones, P. D.: Representing TwentiethCentury Space-Time Climate Variability, Part 2: Development of 1901-1996 Monthly Grids of Terrestrial Surface Climate, J. Climate, 13, 2217-2238, 2000.

New, M., Todd, M., Hulme, M., and Jones, P. D.: Precipitation measurements and trends in the twentieth century, Int. J. Climatol., 21, 1899-1922, 2001.

Nozawa, T., Nagashima, T., Ogura, T., Yokohata, T., Okada, N., and Shiogama, H.: Climate Change Simulations with a Coupled Ocean-Atmosphere GCM Called the Model for Interdisciplinary Research on Climate: MIROC, CGER's Tech. Rep., Natl. Inst. For Environ. Stud., Japan, available at: http://www.cger.nies.go. jp/publications/report/i073/I073.pdf, 2007.

Penman, H. L.: The dependence of transpiration on weather and soil conditions, J. Soil. Sci., 1, 74-89, 1950.

Peterson, T. C. and Vose, R. S.: An Overview of the Global Historical Climatology Network temperature database, B. Am. Meteorol. Soc., 78, 2837-2849, 1997.

Ramanathan, V., Crutzen, P. J., Kiehl, J. T., and Rosenfeld, D.: Aerosols, Climate, and the Hydrological Cycle, Science, 294, 2119-2124, 2001.

Rayner, N. A., Parker, D. E., Horton, E. B., Folland, C. K., Alexander, L. V., Rowell, D. P., Kent, E. C., and Kaplan, A.: Global analyses of sea surface temperature, sea ice, and night marine air temperature since the late nineteenth century, J. Geophys. Res., 108, 4407, doi:10.1029/2002JD002670, 2003.

Roeckner, E., Baeuml, G., Bonventura, L., Brokopf, R., Esch, M., Giorgetta, M., Hagemann, S., Kirchner, I., Kornblueh, L., Manzini, E., Rhodin, A., Schlese, U., Schulzweida, U., and Tompkins, A.: The atmospheric general circulation model
ECHAM5, PART I: Model description, Report 349, Max-PlanckInstitute for Meteorology, available at: http://www.mpimet.mpg. de/fileadmin/models/echam/mpi_report_349.pdf, 2003.

Roeckner, E., Stier, P., Feichter, J., Kloster, S., Esch, M., and Fischer-Bruns, I.: Impact of carbonaceous aerosol emissions on regional climate change, Clim. Dynam., 27, 553-571, 2006.

Sato, M., Hansen, J. E., McCormick, M. P., and Pollack, J. B.: Stratospheric Aerosol Optical Depths, 1850-1990, J. Geophys. Res., 98, 22987-22994, 1993.

Smith, T. M. and Reynolds, R. W.: A Global Merged Land-Air-Sea Surface Temperature Reconstruction Based on Historical Observations, 1880-1997, J. Climate, 18, 2021-2036, 2005.

Solanki, S. K. and Krivova, N. A.: Can solar variability explain global warming since 1970?, J. Geophys. Res. (Space Physics), 108, 1200, doi:10.1029/2002JA009753, 2003.

Stier, P., Feichter, J., Kinne, S., Kloster, S., Vignati, E., Wilson, J., Ganzeveld, L., Tegen, I., Werner, M., Balkanski, Y., Schulz, M., Boucher, O., Minikin, A., and Petzold, A.: The aerosolclimate model ECHAM5-HAM, Atmos. Chem. Phys., 5, 11251156, doi:10.5194/acp-5-1125-2005, 2005.

Stier, P., Feichter, J., Roeckner, E., Kloster, S., and Esch, M.: The evolution of the global aerosol system in a transient climate simulation from 1860 to 2100, Atmos. Chem. Phys., 6, 3059-3076, doi:10.5194/acp-6-3059-2006, 2006.

Thompson, D. W. J., Kennedy, J. J., Wallace, J. M., and Jones, P. D.: A large discontinuity in the mid-twentieth century in observed global-mean surface temperature, Nature, 453, 646-649, 2008.

Trenberth, K. E.: Conceptual Framework for Changes of Extremes of the Hydrological Cycle with Climate Change, Climatic Change, 42, 327-339, 1990.

Trenberth, K. E.: The definition of El Nino, B. Am. Meteorol. Soc., 78, 2771-2777, 1997.

Trenberth, K. E.: Changes in precipitation with climate change, Clim. Res., 47, 123-138, 2011.

Trenberth, K. E. and Dai, A.: Effects of Mount Pinatubo volcanic eruption on the hydrological cycle as an ana$\log$ of geoengineering, Geophys. Res. Let., 34, L15702, doi:10.1029/2007GL030524, 2007.

Van der Ent, R. J., Savenije, H. H. G., Schaefli, B., and Steele-Dunner, S. C.: Origin and fate of atmospheric moisture over continents, Water Resour. Res., 46, W09525, doi:10.1029/2010WR009127, 2010.

Wild, M. and Liepert, B. G.: The Earth radiation balance as driver of the global hydrological cycle, Environ. Res. Lett., 5, 025203, doi:10.1088/1748-9326/5/2/025203, 2010.

Wild, M., Gilgen, H., Roesch, A., Ohmura, A., Long, C. N., Dutton, E. G., Forgan, B., Kallis, A., Russak, V., and Tsvetkov, A.: From Dimming to Brightening: Decadal Changes in Solar Radiation at Earth's surface, Science, 308, 847-850, 2005.

Wild, M., Ohmura, A., and Makowski, K.: Impact of global dimming and brightening on global warming, Geophys. Res. Lett., 34, 04702, doi:10.1029/2006GL028031, 2007.

Wild, M., Grieser, J., and Schär, C.: Combined surface solar brightening and increasing greenhouse effect support recent intensification of the global land-based hydrological cycle, Geophys. Res. Lett., 35, 17706, doi:10.1029/2008GL034842, 2008. 